\title{
Plastic Suffocation: Climate Change Threatens Indigenous Populations and Traditional Ecological Knowledge
}

\author{
Samantha Chisholm Hatfield \\ Oregon Climate Change Research Institute, Oregon State \\ University, USA \\ shatfield@coas.oregonstate.edu
}

Publication Information:

Received 27 November 2019, Accepted 12 November 2019, Available online 16 December 2019

DOI: $10.21463 /$ jmic.2019.08.2.01

\begin{abstract}
Plastic use and waste is a major contributor to climate change worldwide. While attempts to combat and reduce plastic consumption, use, and waste are addressed, remaining unaddressed is the fact that Indigenous populations are more highly impacted by waste plastic and associated climate change affects. These populations are more adversely impacted at higher rates, which is threatening vital Traditional Ecological Knowledge which in turns threatens cultural foundations and cultural lifeways. Plastic waste in traditional marine homeland areas affect Indigenous populations the most, supportive assistance for community is scant, and escape is impossible for place-based Indigenous peoples worldwide.
\end{abstract}

\section{Keywords}

Plastic, Climate Change, Traditional Ecological Knowledge, TEK, Traditional Knowledge, Indigenous, TK, Indigenous Knowledge, IK, Marine, Ocean, Culture 


\section{Introduction}

It's widely known that plastic contributes heavily to degradation of the environment and is a massive contributor to climate change. The general populace worldwide is somewhat immune to the direct impacts during daily life. This is not the case for many Indigenous populations however, who rely on traditional resources to economically sustain themselves as well as uphold their traditional cultural systems and practices. It has long been established that culture, sovereignty lifeways, and other aspects of Indigenous people in the United States are being affected by climate change (Parker et al. 2006, Bennett et al. 2014, Maldonado et al. 2014, Norton-Smith et al 2016). Extinction of Traditional Ecological Knowledge (TEK) is an ongoing danger to many Indigenous populations, not just those in the United States. This threat is ongoing, increasing, and stemming from the direct, and daily, impacts of climate change. Much of that threat is directly from plastic.

As Indigenous populations continue to grapple with forced adaptations from environmental pressures, they also simultaneously continue to deliberate how to sustain and cultivate their Traditional Ecological Knowledge. TEK has continued, being upheld and utilized in Indigenous communities for cultural and sustainability practices, having been passed down through multiple generations, many since time immemorial. Climate change is affecting those TEK systems worldwide in very direct and devastating manners. Many of the Indigenous populations facing these issues are marine faring communities who have long been articulating environmental changes attributed to climate change, by sea as well as on land. Longstanding documentation of environmental change has been articulated and addressed such as temperature changes, warming waters, increased toxic blooms, declining varieties of traditional resources, migration of traditional species and invasive species. These discussions and documentations have transpired for several decades through Traditional Ecological Knowledge. Articulation of these occurrences have been noted as preceding prior to the widely spread western science knowledge of global warming and climate change (Chisholm Hatfield 2009, Turner and Clifton, 2009).

Indigenous island and coastal populations are heavily reliant on the marine resources they have that is integral to their cultural system (Shepherd, S. and Terry, A., 2004, Lepofsky and Caldwell 2013, Weiss et al, 2013, Chisholm Hatfield 2018). These Indigenous marine communities have an intimate understanding of the Traditional Ecological Knowledge that relates to both the ocean, as well as the beaches and mudflats of their homelands. Complex systems such as these require a delicate balance and communities must possess a sophisticated and intricate understanding of the coordination of multiple ecosystems which work cohesively in tandem with one another. Disruption of any aspect of these systems could mean devastating effects for Indigenous communities due to the traditional cultural practices and natural resource reliance these communities possess and rely upon.

\section{Plastics: A Huge Contribution to Climate Change}

Plastic and climate change are linked in a variety of ways. From air quality to ocean toxicity, plastic bags contribute to eco-system disruption. Habitat destruction, fossil fuel emissions, and plastic pollution are some of the ways that plastic bags and climate change are linked, cannot be separated. But the build-up of plastic in our oceans is a greater cause of 
eco-system disruption. An estimated 100,000 marine animals die each year from suffocating on or ingesting bags. Approximately forty percent of plastic worldwide is utilized as packaging material. There are three manners of processing packaging material: landfill, incineration, or recycling. Since packaging is most often single-use, much of that forty percent is sent to landfills. Of the plastic that is sent to a landfill, some is light enough that it's unable to be contained and disposed of properly, and blows away, often landing in bodies of water. On average, a mere nine percent of that plastic is recycled worldwide (Parker 2018). Incineration of plastics released in 2015 equalled 5.9 metric tons of carbon dioxide in the United States alone (CIEL Report 2019 Fig. 2). World Energy Council projections anticipate this amount to increase to a staggering 49 million metric tons by 2030, and 91 million metric tons by 2050 if plastic production and subsequent incineration continues as predicted (Bauman par. 13)

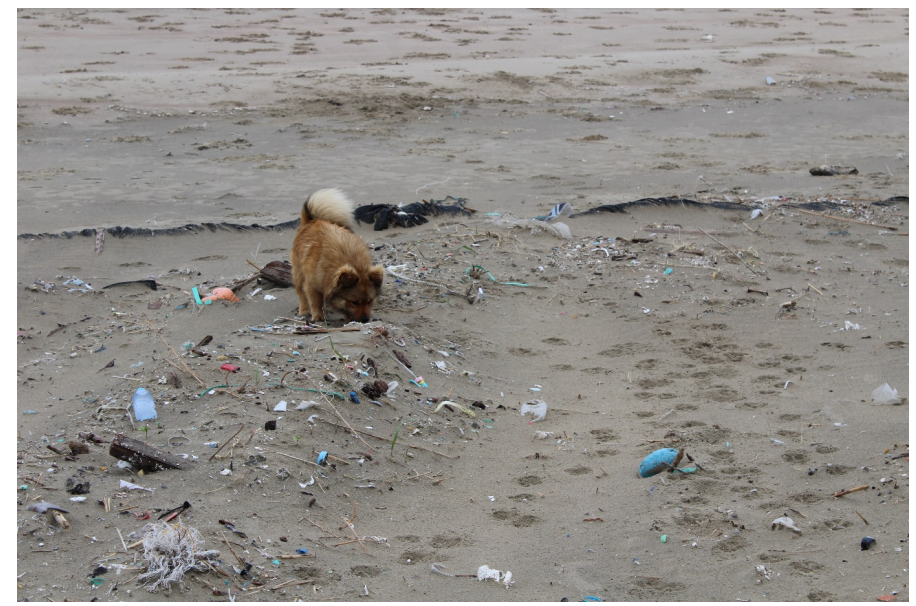

Fig 1. A dog on South Korea island beach rummages through plastic waste washed ashore (Photo credit copyright: Samantha Chisholm Hatfield)

Incineration, linked as a contributor to climate change, has become a colossal environmental justice issue worldwide that is not being adequately addressed by most governments. Incineration itself is considered to be one of the largest environmental injustices, not only in the United States, but worldwide. Most of the communities who are subjected to the fallout of incineration pollution, are those who are the lowest of the contributors of the initial pollution, those who are predominately communities of low income and people of color (Bauman, par. 15). Even if plastics go to a landfill, some are light enough to blow in the wind and enter waterways.

Plastics can become more detrimental upon entering waterways. Plastics can break down into smaller pieces, deemed microplastics, via biodegradation, exposure to the sun, heat, or water. Microplastics can then disperse across the globe, including reaching to deep ocean depths. In addition, toxic chemicals can bind to microplastics, which then creates a largely undetectable poison to animals, which they then consume. Plastics also harm animals in other ways, such as entanglement. (Bauman par. 25) 


\section{Why Plastic in Marine Environments is Worse}

Glaciers and ice sheets in polar and mountain regions are losing mass, contributing to an increasing rate of sea level rise, together with expansion of the warmer ocean. While sea level has risen globally by around $15 \mathrm{~cm}$ during the 20th century, it is currently rising more than twice as fast, at $3.6 \mathrm{~mm}$ per year and accelerating, according to the IPCC 2019 Press Release. It is projected that sea levels will continue to rise for centuries, and could reach around $30-60 \mathrm{~cm}$ by the year 2100. This rate is estimated even if greenhouse gas emissions are sharply reduced currently, and if global warming is limited to well below $2^{\circ} \mathrm{C}$. However, if temperatures and emissions are not curbed at the previous level, sea levels could rise to around 60-110 cm (IPCC Press Release 2019).

While the sea level is rising, plastics continue to litter the oceans in catastrophic amounts. It has been estimated that by the year 2050 there will be more pieces of plastic in the seas than there are numbers of fish. (MacArthur, 2017, Wearden, 2018) Sarah-Jeanne Royer at Scripps Institution of Oceanography has found that low-density polyethylene, one of the most common types of plastics found in the ocean, releases greenhouse gases as it breaks down in the environment. (Royer et al. 2018) Ocean University of China researchers found microplastics reduced microalgae growth, as well as the efficiency of photosynthesis (Zhang et al 2017). Producing more microplastics could degrade plankton's ability to remove carbon dioxide from the atmosphere, thus creating more problematic issues and further contributing to climate change.

\section{Plastic: A Larger Threat to Indigenous Marine Populations Relying on TEK}

Climate change impacts were being noted in academia years before mainstream systems were brought onboard and first began accepting these notations of impact (Abate and Kronk, 2013). However, Indigenous populations have been noting climate change impacts for significant amounts of time prior to academic systems' acknowledgements of climate change (Krupnik and Jolly 2002, Turner and Clifton 2009, Chisholm Hatfield 2009, 2014, 2018, Green et al 2010, Pareek and Trivedi 2011, Kalanda-Joshua et al 2011). This Indigenous Science TEK information has long been ignored or regarded as simplistic "storytelling" and considered without basis. In recent years however, TEK has been a rapidly growing information system recognized by science, policy, and stakeholders, and has increasingly been relied upon for information that has long eluded western-based science.

Within this growing paradigm is the fact that most marine populations who remain in traditional homeland areas are also adjusting, adapting, and reliant on TEK practices and adaptations that can assist them through climate change impacts. Indigenous populations adjust and manipulate surrounding environments for optimal sustainability and for accordance with cultural belief and adherences (Hong et al 2007, Hong et al 2010). Some of these behaviors are sustainability techniques that are effective and regularly employed on scales designed to fit for Indigenous communities.

It's already widely documented that seas and sealife, is being suffocated by the amount of plastic waste (Dharmamony, 2018). Much of that waste has been preventable, but overwhelmingly contributes to pollution, and climate change. In 
addition, plastics are entering food chains at all levels and have been detected, but specifically in seafoods (Seltenrich 2015). Many Indigenous populations' diet consists of and relies solely, or to a majority on seafoods. These foods, both plant and animal, are being impacted and transferring the plastic waste into consumption on a regular basis, which impacts and potentially compromises overall health through ingestion of foreign and toxic substances.

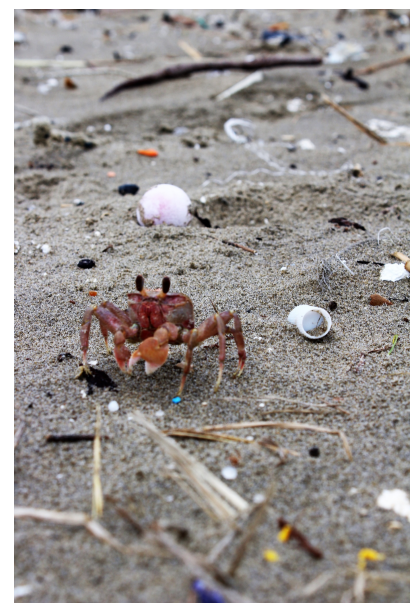

Fig 2. A crab amid broken down plastic (Photo credit copyright: Samantha Chisholm Hatfield)

Small island populations, which espouse and support many Indigenous populations are vital to insert into the front of the ongoing climate change discussions. F. Halais emphasized the points that small island developing states (SIDS) are the custodians to much of the world's oceans. These small island states have exclusive economic zones (EEZs), and thirty percent of all oceans and seas are controlled, with EEzs that exceed the islands' landmasses. While these islands host natural resources that are impressive in size and quantity, they additionally have extremely limited capacity to fight climate change impacts and environmental degradation "...from the depletion of fish stocks to coastal erosion, ocean plastic pollution or coral reef degradation, SIDS are facing mounting difficulties in practicing good stewardship over their most precious assets." (Halais par. 1,2)

\section{Climate Change Impacts and Indigenous Populations}

Indigenous populations are affected by climate change impacts faster and more stridently, being connected to the land, utilizing its resources and in actuality, impacted by even slight changes. Populations are continuously both historically and culturally connected, as well as renewing and continually adjusting, adapting, and connecting to the land as it changes, utilizing its resources and being more attuned to even slight changes than others.

The majority of narratives are from Indigenous communities located in locales with considerable measurable temperature increases. This is important because temperature rise impacts common traditional lifeway behaviors, as well as resources. These temperature rises have been regularly noted as changing from the Indigenous populations residing on, and utilizing traditional resources and areas. 
Indigenous peoples worldwide are the most adversely, and disproportionately affected by climate change impacts (Zimmerman 2005, Shepard and Corbin-Mark 2009, Davis 2010, Theriault 2012, Green and Minchin 2014). This is largely a result of their historic dependence on local biological diversity, ecosystem services and natural landscapes as a source of sustenance, subsistence, and well-being being disputed and altered to the point of not being able to continue practicing sustainability practices and cultural traditional practices.

The core identity of Indigenous peoples is intimately linked with their homeland areas and traditional food sources, and often is indistinguishable when attempted to separate aspects of one from the other. These homeland areas are typically located predominantly at locations that intersect where mainstream non-Indigenous activities also occur. Areas that utilize adjoining, overlapping, or adjacent regions for economic and recreational gain by non-Indigenous groups. This intersectionality can present problems and often are in places where access to, or of, water is imminent, and where pollution is apparent, rampant, and problematic (Colchester 1994, Chi 2001, Maddocks and Rayner 2003, Nuttall 2005, Hakim et al 2009, Hoover et al 2012, Whyte 2016).

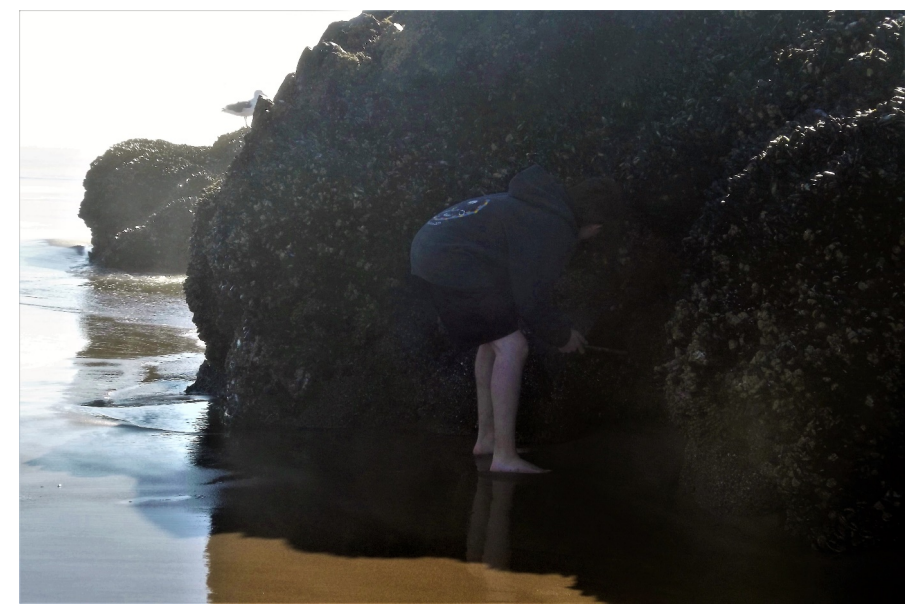

Fig 3. Confederated Tribes of Siletz member in a traditional shellfish gathering area off the Oregon Coast (Photo Credit copyright: Samantha Chisholm Hatfield)

As IPCC press release stated threats will continue, those along coastlines and Indigenous populations relying on the oceans will be at an even greater increased risk. "Sea level rise will increase the frequency of extreme sea level events, which occur for example during high tides and intense storms." (IPCC Press Release 2019)

Even slight changes affect Indigenous populations in heightened degrees, more so than other non-Indigenous groups, due to being place-based people reliant on, and connected to, their environments. These communities relying on and engaging in TEK practices and mannerisms need to be able to continue to do so for their health and well-being, not only for their cultural survival. They cannot leave, nor are immune to the slightest changes in their immediate place-based environment experiences. Daily sustainable living practices which often are rooted in cultural traditional behaviors are foundational for Traditional Ecological Knowledge practices (Nuttall et al 2005, Davidson-Hunt and O'Flaherty 2007, Busilacchi et al 2013, Pascua et al 2017, De Leeuw 2018). These can include, fishing, gathering, collection of natural materials, and hunting. When environments and the natural resources in these areas are affected, not only are cultures 
and traditional practices threatened, but additionally so are the economic gains that Indigenous groups both contribute to, and benefit from (Altman et al 2018).

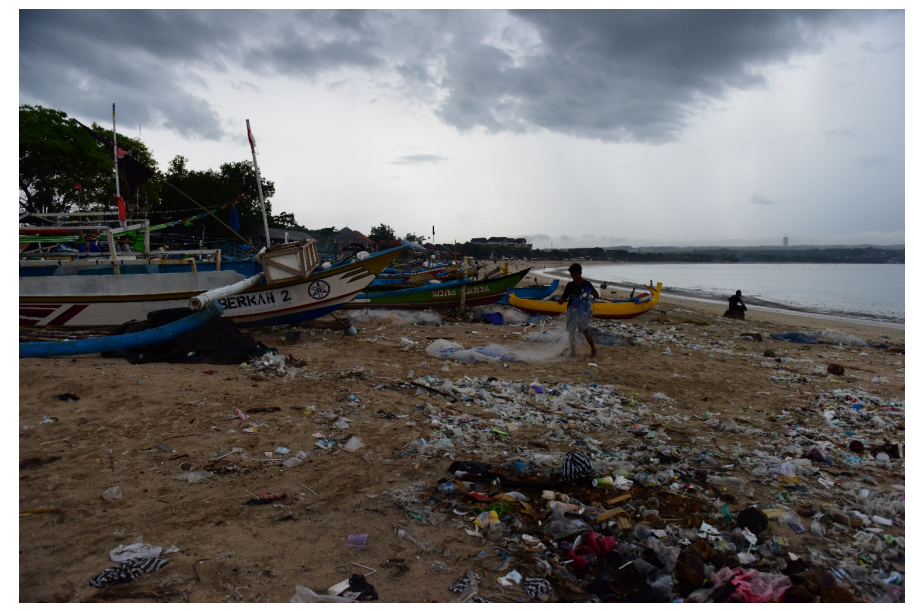

Fig 4. Fishermen on the coast of Bali working around washed ashore waste (Photo Credit copyright: Sun Kee Hong)

\section{Conclusion and Recommendation}

Most non-Indigenous people are immune to the impacts of climate change until it has affected some aspect of their life in a way that disrupted their routine. As many Indigenous communities worldwide were noting and discussing climate change impacts openly decades ago, the discussion was not obtaining nearly enough attention as much as the topic currently is garnering. These impacts to the environment have been increasingly threatening livelihoods as well as crucial cultural foundations, impacting all aspects of cultural practices related to marine environments. Many Indigenous communities survive and/or, thrive in capitalistic endeavors which involve sea-faring or marine-faring activities. These marine natural resources not only are used in sustainable living practices for communities and environments, but also often involve subsistence living and needed income generation as well. Abandoning such practices by Indigenous groups would involve cultural abandonment as well, which is neither practical, nor ethical. Forced homeland abandonments of Indigenous Peoples has been the crux of genocidal methods; as such, prevention of further forced practices on any cultural group is imperative. Indigenous peoples worldwide are the first to witness, document, and be affected by climate change impacts. It is imperative that listening, acknowledging then assisting Indigenous efforts to combat and protect ecosystems be enabled and mobilized. The implications of climate change have been shown to have a cascading effect on those non-Indigenous who are not relying on land and natural resources first-hand on a regular basis in a cultural, subsistence-reliant manner. Ensuring that waterways are cleaned, cleared of plastic garbage, and plastics are prevented from entering waterways, is imperative to the health and well-being of Indigenous and nonIndigenous populations. This will also assist in the fight against climate change impacts overall, ensuring slowed degradation of environmental systems both terrestrial as well as aquatic. While there are ongoing reports and acknowledgements of plastic riddling seas and threatening sea life, there are also engaging discussions addressing the topic and how to combat it, through a variety of means. One which has been suggested is through approach of a treaty 
(Tiller and Nyman, 2018). While this may seem innovative, treaties already cover expansive territories regarding Indigenous in the Unites States, and none have included this topic of endangered protected areas, so it would seem futile to believe that inclusion of this topic in any form of a treaty, would have any teeth so to speak.

It seems that the manner of addressment needs to be included into areas where economic forums and protection of cultural groups are the most vital, and the strongest. This topic has been long overdue in terms of how impacts are, and have been, impacting Indigenous communities which also then impact lifeways worldwide, including economies and cultures. Addressing and including the information embedded into Traditional Ecological Knowledge, which often includes documentation of climate change impacts in various ways, should be an area where scientists, policy makers, management systems, and stakeholders all listen more keenly to what is being, and has been, articulated. This approach would ensure a better informed and well-rounded tactic, which could be readily employed collaboratively and with enhanced methodology to effectively combat climate change.

\section{References}

Abate, R.S. and Kronk, E.A., 2013. Commonality among unique indigenous communities: An introduction to climate change and its impacts on indigenous peoples. Tulane Environmental Law Journal, pp.179-195.

Altman, J., Larsen, L. and Buchanan, G.J., 2018. The environmental significance of the Indigenous estate: natural resource management as economic development in remote Australia.

Bauman, B. "Why plastics can be garbage for the climate." Yale Climate Connections, 23 Aug 2019,

https://www.yaleclimateconnections.org/2019/08/how-plastics-contribute-to-climate-change/. Accessed 1 Nov 2019.

Busilacchi, S., Russ, G.R., Williams, A.J., Sutton, S.G. and Begg, G.A., 2013. The role of subsistence fishing in the hybrid economy of an indigenous community. Marine Policy, 37, pp.183-191.

Chi, C.C., 2001. Capitalist expansion and indigenous land rights: emerging environmental justice issues in Taiwan. The Asia Pacific Journal of Anthropology, 2(2), pp.135-153.

Chisholm Hatfield, S., 2009. Traditional ecological knowledge of Siletz tribal members. Oregon State University Press.

Chisholm Hatfield, Samantha., Marino, Elizabeth, Whyte, Kyle Powys, Dello, Kathie D., and Mote, Philip W. 2018. Indian Time: Time, Seasonality, and Culture in Traditional Ecological Knowledge of Climate Change. Ecological Processes. DOI: 10.1186/s13717-018-0136-6

CIEL Report. "Plastic \& Climate: The Hidden Costs of Plastic Planet." Center for International Environmental Law, May 2019, https://www.ciel.org/reports/plastic-health-the-hidden-costs-of-a-plastic-planet-may-2019/. Accessed 9 Nov. 2019.

Colchester, M., 1994. Salvaging nature: indigenous peoples, protected areas and biodiversity conservation (Vol. 55). Diane Publishing.

Davidson-Hunt, I.J. and Michael O'Flaherty, R., 2007. Researchers, indigenous peoples, and place-based learning communities. Society and natural resources, 20(4), pp.291-305.

Davis, S.H., 2010. Indigenous peoples and climate change. The International Indigenous Policy Journal, 1(1), p.2.

Fields, P.A., Graham, J.B., Rosenblatt, R.H. and Somero, G.N., 1993. Effects of expected global climate change on marine faunas. Trends in Ecology \& Evolution, 8(10), pp.361-367. 
Green, D. and Minchin, L., 2014. Living on climate-changed country: Indigenous health, well-being and climate change in remote Australian communities. EcoHealth, 11(2), pp.263-272.

Green, D., Billy, J. and Tapim, A., 2010. Indigenous Australians' knowledge of weather and climate. Climatic Change, 100(2), pp.337-354.

Hakim, L., Kim, J.E. and Hong, S.K., 2009. Cultural landscape and ecotourism in Bali Island, Indonesia. Journal of Ecology and environment, 32(1), pp.1-8.

Halais, F. "How small islands can harness the ocean economy." Devex, 24 July 2019, https://www.devex.com/news/how-small-islands-canharness-the-ocean-economy-95290. Accessed 29 Oct. 2019.

Hong, S.K., Song, I.J. and Wu, J., 2007. Fengshui theory in urban landscape planning. Urban ecosystems, 10(3), pp.221-237.

Hong, S.K., Wu, J., Kim, J.E. and Nakagoshi, N. eds., 2010. Landscape ecology in Asian cultures. Springer Science \& Business Media.

Hoover, E., Cook, K., Plain, R., Sanchez, K., Waghiyi, V., Miller, P., Dufault, R., Sislin, C. and Carpenter, D.O., 2012. Indigenous peoples of North America: environmental exposures and reproductive justice. Environmental Health Perspectives, 120(12), pp.1645-1649.

Hughes, K.A. and Convey, P., 2010. The protection of Antarctic terrestrial ecosystems from inter-and intra-continental transfer of nonindigenous species by human activities: a review of current systems and practices. Global Environmental Change, 20(1), pp.96-112.

IPCC, 2019: Summary for Policymakers. In: IPCC Special Report on the Ocean and Cryosphere in a Changing Climate [H.-O. Pörtner, D.C. Roberts, V. Masson-Delmotte, P. Zhai, M. Tignor, E. Poloczanska, K. Mintenbeck, M. Nicolai, A. Okem, J. Petzold, B. Rama, N. Weyer (eds.)]. In press. Poloczanska, K. Mintenbeck, M. Nicolai, A. Okem, J. Petzold, B. Rama, N. Weyer (eds.)], 25 Sept 2019, https://www.ipcc.ch/2019/09/25/srocc-press-release/. Accessed 27 Oct. 2019.

Kalanda-Joshua, M., Ngongondo, C., Chipeta, L. and Mpembeka, F., 2011. Integrating indigenous knowledge with conventional science: Enhancing localised climate and weather forecasts in Nessa, Mulanje, Malawi. Physics and Chemistry of the Earth, Parts A/B/C, 36(14-15), pp.996-1003.

Krupnik, I. and Jolly, D., 2002. The Earth Is Faster Now: Indigenous Observations of Arctic Environmental Change. Frontiers in Polar Social Science. Arctic Research Consortium of the United States, 3535 College Road, Suite 101, Fairbanks, AK 99709.

Lepofsky, D. and Caldwell, M., 2013. Indigenous marine resource management on the Northwest Coast of North America. Ecological Processes, 2(1), pp.1-12.

Lewis, P.N., Riddle, M.J. and Hewitt, C.L., 2004. Management of exogenous threats to Antarctica and the sub-Antarctic Islands: balancing risks from TBT and non-indigenous marine organisms. Marine pollution bulletin, 49(11-12), pp.999-1005.

Lewis, P.N., Riddle, M.J. and Smith, S.D., 2005. Assisted passage or passive drift: a comparison of alternative transport mechanisms for nonindigenous coastal species into the Southern Ocean. Antarctic Science, 17(2), pp.183-191.

MacArthur, Ellen. "Beyond plastic waste." (2017): 843-843.

Maddocks, I. and Rayner, R.G., 2003. Issues in palliative care for Indigenous communities. Medical journal of Australia, 179, pp.S17-S19.

Norton-Smith, K., Lynn, K., Chief, K., Cozzetto, K., Donatuto, J., Redsteer, M.H., Kruger, L.E., Maldonado, J., Viles, C. and Whyte, K.P., 2016. Climate change and indigenous peoples: a synthesis of current impacts and experiences. Gen. Tech. Rep. PNW-GTR-944. Portland, OR: US Department of Agriculture, Forest Service, Pacific Northwest Research Station. 136 p., 944.

Nuttall, M., 2005. Protecting the Arctic: Indigenous peoples and cultural survival. Routledge.

Nuttall, M., Berkes, F., Forbes, B., Kofinas, G., Vlassova, T. and Wenzel, G., 2005. Hunting, herding, fishing and gathering: indigenous peoples and renewable resource use in the Arctic. Arctic climate impact assessment, pp.649-690.

Pareek, A. and Trivedi, P.C., 2011. Cultural values and indigenous knowledge of climate change and disaster prediction in Rajasthan, India. 
Parker, Laura. 2018. "Planet or Plastic”, 20 Dec. 2018, https://www.nationalgeographic.com/news/2017/07/plastic-produced-recycling-wasteocean-trash-debris-environment/. Accessed 9 Nov 2019.

Pascua, P.A., McMillen, H., Ticktin, T., Vaughan, M. and Winter, K.B., 2017. Beyond services: A process and framework to incorporate cultural, genealogical, place-based, and indigenous relationships in ecosystem service assessments. Ecosystem Services, 26, pp.465-475.

Royer, S.J., Ferron, S., Wilson, S.T. and Karl, D.M., 2018. Production of methane and ethylene from plastic in the environment. PloS one, 13(8), p.e0200574.

Seltenrich, N., 2015. New link in the food chain? Marine plastic pollution and seafood safety.

Shepard, P.M. and Corbin-Mark, C., 2009. Climate justice. Environmental Justice, 2(4), pp.163-166.

Shepherd, S. and Terry, A., 2004. The Role of indigenous communities in natural resource management: the Bajau of the Tukangbesi Archipelago, Indonesia. Geography, pp.204-213.

Theriault, S., 2012. Canadian Indigenous Peoples and Climate Change: The Potential for Arctic Land Claim Agreements to Address Changing Environmental Conditions. Randall Abate et Elizabeth Kronk (dirs.), Climate Change, Indigenous Peoples and the Search for Legal Remedies, Cheltenham, Edward Elgar Publishing.

Tiller, R. and Nyman, E., 2018. Ocean plastics and the BBNJ treaty-is plastic frightening enough to insert itself into the BBNJ treaty, or do we need to wait for a treaty of its own?. Journal of Environmental Studies and Sciences, 8(4), pp.411-415.

Turner, N.J. and Clifton, H., 2009. "It's so different today": Climate change and indigenous lifeways in British Columbia, Canada. Global Environmental Change, 19(2), pp.180-190.

Turner, N.J. and Clifton, H., 2009. "It's so different today": Climate change and indigenous lifeways in British Columbia, Canada. Global Environmental Change, 19(2), pp.180-190.

Wearden, G., 2018. More plastic than fish in the sea by 2050, says Ellen MacArthur. The Guardian. https://www. theguardian. com/business/2016/jan/19/more-plastic-than-fish-in-the-sea-by-2050-warns-ellen-macarthur. Accessed, 11/5/19.

Weiss, K., Hamann, M. and Marsh, H., 2013. Bridging knowledges: understanding and applying indigenous and western scientific knowledge for marine wildlife management. Society \& Natural Resources, 26(3), pp.285-302.

Whyte, K., 2016. Indigenous food systems, environmental justice, and settler-industrial states.

Zhang, C., Chen, X., Wang, J. and Tan, L., 2017. Toxic effects of microplastic on marine microalgae Skeletonema costatum: interactions between microplastic and algae. Environmental pollution, 220, pp.1282-1288.

Zimmerman, E.M., 2005. Valuing Traditional Ecological Knowledge: Incorporating the Experience of Indigenous People into Global Climate Change Policies. NYU Envtl. LJ, 13, p.803. 